\title{
Phytochemicals: Extraction and Preliminary Investigation of Bioactive Compounds from Rumex Vesicarius and Terminalia Catappa Plant
}

\author{
Anandika Suryavanshi ${ }^{1 *}$, Anand Murari Saxena ${ }^{2}$, Payal Mago ${ }^{3}$ and Manisha Khatri ${ }^{4}$ \\ ${ }^{1 \& 2}$ Department of Zoology, University of Lucknow, Lucknow, Uttar Pradesh, India \\ ${ }^{3 \& 4}$ Saheed Rajguru College of Applied Sciences for Women, University of Delhi, Delhi, India \\ *Corresponding Author \\ E-Mail: anandika02@gmail.com
}

\begin{abstract}
The present study was carried out for the determination of bioactive compounds from different extracts of Terminalia catappa and Rumex vesicarius. The plants are mines of several bioactive compounds also called as phytochemical compounds. These bioactive compounds are responsible for imparting such a potential medicinal property in the plants. The medicinal plant contains various types of bioactive compounds including phenols, alkaloids, terpenoids, tannins, glycosides, flavonoids etc. These bioactive compounds take part in various metabolic pathways and impart their effect. Terminalia catappa and Rumex vesicarius are such medicinal plants which are being used for medicinal purposes for long time. Both of them are rich source of potential bioactive compounds and hence carry out several biological activities effective for the treatment of various diseases. Hence the study focuses on determining the types of bioactive compounds they acquire. For this the leaves of $T$. catappa and dry stems of $R$. vesicarius were used for the extraction using different solvents with soxhlet method. The extract of different solvents was analyzed for the phytochemical test. The results obtained revealed that the type of solvents is crucial in determining the type of bioactive compounds to be present in extract. The results showed that ethanol and methanol are good solvent choice for extraction for these two plants. The results concludes that the presence of such potential and effective bioactive compounds in their extract makes them important medicinal plants and are hence employed for several researches and also used for treatment of various kinds of diseases.
\end{abstract}

Keywords: Terminalia Catappa, Rumex Vesicarius, Phytochemical Compounds, Medicinal Properties

\section{INTRODUCTION}

The nature is filled with an astonishing diversity of plants with the potential to be used as the medicinal plant. Varieties of plants are distributed throughout the world carrying the potent medicinal properties to treat various disease conditions. The potentiality of these plants to carry out such important and remarkable function is due the presence of different kinds of novel compounds, in their different body parts, called as the bioactive compounds or phytochemical compounds. These phytochemical or bioactive compounds are referred as the plant derived chemicals capable of disease prevention and hence important and novel for humans (Chung et al., 1999). The phytochemical compounds can be derived from various plant parts as well as different parts may different bioactive compound. The major plant part used for the extraction of bioactive compounds incudes the leaves, bark, flower, root, seed, fruit and stems as well, this indicates that any part of plant could bear these bioactive compounds (Gordon et al., 2001).

The bioactive compounds carry out their medicinal property through interfering with the metabolic pathway of the infecting microbe or on different biological machinery of animals and humans as well. The bioactive compounds act the determinants of the host-microbe relationship whether microbe is pathogenic or symbiotic. The remarkable medicinal properties of the bioactive compounds have made them as the centre of research, in order to explore and exploit them for welfare of mankind. The bioactive compounds carrying out its natural origin has no side effects on the individual being treated with them and this makes them more efficient to replace the chemical drugs that somewhat cause some side effects. The knowledge of the presence of bioactive compounds in different plant parts could help us to deduce the importance of plant in disease treatment. For a plant to be used for medicinal purpose the bioactive compounds extraction, identification and purification is very necessary.

Terminalia catappa is a member of Combretaceae family that generally grows in the tropical and subtropical countries and has the Meridional Asian origin. The tree is a huge spreading tree fairly distributed throughout the coastal area of tropics. The tree is well known to grow in freely drained sandy soil with well aeration (). Various parts of the plant including leaf, bark and fruit are used in the traditional medicine treatment against diarrhea. The leaves of the plant have been reported to possess the antioxidant, antiinflammatory, anti-diabetic, hepato-protective and anti HIV reverse transcriptase (Tang et al., 2004). The anti-diabetic activity of the plant is studied in various animal model and the result obtained categories the plant as an effective measure for diabetes treatment.

The studies carried out also concluded that the extract effectively leads the reduction of fasting glucose level in blood, serum triglycerides, serum urea, low density lipoprotein and serum cholesterol (Ahmmed, 2005). The presence of wide range of bioactive compounds with 
potential activity as well has attracted to carry out the study on its phytochemical constituents. The concentration of bioactive compounds present in the extract depends upon the method employed for extraction and the choice of solvent is also considered (Hayouni et al., 2007).

Rumex vesicarius is a branched herb of the family Polygonaceae. It is widely distributed in India and is used as green vegetable, also termed Bladder dock. The whole plant body is found to be rich in bioactive compounds. The juice of this plant is commonly used for the treatment of stomach heat, toothache and it improves the appetite as well. The fruits of the plant are eaten against Jaundice, constipation and indigestion. Seeds are helpful in treatment of dysentery (Yusuf et al., 2009). The chemical analysis of this pant extract has revealed the presence of several bioactive compounds like polyphenols, flavonoids, carotenoids, tocopherols and ascorbic acid in different extracts (ElHawary et al., 2011). Like other, Rumex vesicarius carry out the medicinal important tag due to its bioactive compounds. The plant contains flavonoids like vitexin, orietin and isoorietin, anthraquinones like emodin and chrysophanol present in the roots. Along with them plant is also rich in quinones, carotenoids, vitamins, phenols, tannins, saponins, proteins, and organic acids. The plant is full of several important minerals like $\mathrm{K}, \mathrm{Na}, \mathrm{Ca}, \mathrm{Mg}, \mathrm{Fe}$, $\mathrm{Mn}$ and $\mathrm{Cu}$ (Mostafa et al., 2011; Prasad and Ramakrishnan, 2012).

\section{MATERIAL AND METHODOLOGY}

A. Collection of Sample: The leaf sample of Terminalia catappa and stem samples of Rumex vesicarius was collected from Wazirabad garden of New-Delhi . The sample was stored in a clean and dry vessel in the research laboratory.

B. Extract Preparation: For the extract preparation $100 \mathrm{gm}$ of ground sample of bark was refluxed with 1litre of the solvent (ethanol, acetone, methanol, n-hexane and water) at $70^{\circ} \mathrm{C}$ temperature. This was carried out for 48 hour in the soxhlet apparatus. Then the liquid extract was obtained by vacuum filtration method using the Whatman filter paper No. 1. Then the filtrate extract was concentrated using the rotatory evaporator and this was followed by freeze drying. The extract was then stored at $4^{\circ} \mathrm{C}$ till any further analysis was carried out.

C. Phytochemical Analysis of the Extract: The extracts obtained from the above process were then carried out for the phytochemical analysis. The phytochemical analysis was carried out for different bioactive compound determination using different standard procedure. This analysis was carried out in the similar way for all the extracts.

1. Test for Alkaloids: This was done by Mayer's test. For the test $1 \mathrm{ml}$ of plant extract was mixed with $3 \mathrm{ml}$ of ammonia solution and the mixture was allowed to stand for few minutes. Then $10 \mathrm{ml}$ of chloroform was added to the same tube. The tube was shaken and the content was filtered. The chloroform was evaporated by keeping the tubes in water bath. Then $3 \mathrm{ml}$ of Mayer's reagent was added to the tube. The result interpretation is by the formation of cream colour precipitate indicating presence of alkaloids.

2. Test for Amino acids: For this $1 \mathrm{ml}$ of plant extract was treated with $0.5 \mathrm{ml}$ of the Ninhydrin reagent $(0.25 \%)$. The content was boiled for few minutes. The result interpretation is by the formation of blue colour indication presence of Amino acid in the extracts.

3. Test for Flavonoids: The test was performed by Alkaline Reagent test. For this $1 \mathrm{ml}$ of plant extract was treated with dilute sodium hydroxide solution that leads to appearance of intense yellow colour which fades away after addition of few drops of dilute acid. The result is interpreted as positive when the colour disappears indication presence of flavonoids.

4. Test for Glycosides: Keller-Killiani method was used for determining the test result. In the test $1 \mathrm{ml}$ of plant extract was treated with few drops of glacial acetic acid and ferric chloride solution and this was content was mixed thoroughly. Next concentrated sulphuric acid was added to the tube and the tube was observed for the formation of two layers that is lower reddish brown layer and upper acetic acid layer. The result interpretation is done after the upper layer turns bluish green indicating the presence of glycosides in the sample.

5. Test for Phenols: The presence of phenols in the extract was assessed through Ferric chloride test. $1 \mathrm{ml}$ of plant extract was treated with 3-4 drops of ferric chloride solution. The positive result is indicated by the formation of a bluish black colour indicating the presence of phenols.

6. Test for Proteins: Test for the presence of protein was carried out by Xanthoprotic test. In this test $1 \mathrm{ml}$ plant extract was treated with few drops of concentrated nitric acid. Formation of yellow colour is interpreted as the positive result for the test.

7. Test for Saponins: Froth test was applied to determine the presence of Saponins in the plant extract sample. $1 \mathrm{ml}$ of plant extract was diluted with $20 \mathrm{ml}$ of distilled water. The content was shaken vigorously for 15 minutes. The formation of a $1 \mathrm{~cm}$ thick stable froth layer is taken as the positive result for the test and indicates the presence of saponins.

8. Test for Steroids: Steroid test was carried out Liebermann Burchard test. For this $1 \mathrm{ml}$ of plant extract was mixed with $10 \mathrm{ml}$ of chloroform. Then equal volume of concentrated sulphuric acid was added to the tubes. This leads to formation of two layers, the upper layer turns red and the sulphuric acid layer shows yellow with green fluorescence and this indicates the presence of steroids. 


\section{RESULTS AND DISCUSSION}

Extracts from both the samples were obtained with all the solvents by soxhlet extraction method. All the extracts were carried out for the phytochemical analysis using above mentioned procedures. The analysis result showed the presence of some bioactive agents in all the extracts. The type of bioactive agent present in the extracts varied with the type of solvents like Flavonoids were present in the methanolic, acetone, aqueous and $\mathrm{n}$-hexane extract of Terminalia catappa while it was absent in the methanolic extract. Same variation was observed in the case of Rumex vesicarius as glycosides were present in ethanolic and methanolic extract while it was in acetone, n-hexane and aqueous extract. This kind of variation was also observed with other bioactive compounds from both the samples.

TABle I Showing The Phytochemical Analysis Results For Different EXtracts Of Terminalia Catappa

\begin{tabular}{|l|c|c|c|c|c|}
\hline \multirow{2}{*}{ Name of the phytochemical } & \multicolumn{5}{|c|}{ Results (+) Present ; (-) Absent } \\
\cline { 2 - 6 } & $\begin{array}{c}\text { Ethanolic } \\
\text { Extract }\end{array}$ & Methanolic Extract & $\begin{array}{c}\text { Acetone } \\
\text { Extract }\end{array}$ & $\begin{array}{c}\text { Aqueous } \\
\text { Extract }\end{array}$ & $\begin{array}{c}\text { n-Hexane } \\
\text { Extract }\end{array}$ \\
\hline Alkaloids & - & - & - & - & - \\
\hline Amino Acids & - & - & - & - & - \\
\hline Flavonoids & - & + & + & + & + \\
\hline Glycosides & + & + & - & - & - \\
\hline Phenols & + & + & - & + & - \\
\hline Proteins & - & - & + & + & + \\
\hline Saponins & - & - & - & - & - \\
\hline Steroids & + & + & - & - & - \\
\hline
\end{tabular}

Table II Showing The Phytochemical Analysis Results For Different Extracts Of Rumex Vesicarius

\begin{tabular}{|l|c|c|c|c|c|}
\hline \multirow{2}{*}{ Name of the phytochemical } & \multicolumn{5}{|c|}{ Results (+) Present ; (-) Absent } \\
\cline { 2 - 6 } & $\begin{array}{c}\text { Ethanolic } \\
\text { Extract }\end{array}$ & Methanolic Extract & $\begin{array}{c}\text { Acetone } \\
\text { Extract }\end{array}$ & $\begin{array}{c}\text { Aqueous } \\
\text { Extract }\end{array}$ & $\begin{array}{c}\text { n-Hexane } \\
\text { Extract }\end{array}$ \\
\hline Alkaloids & - & - & - & - & - \\
\hline Amino Acids & - & + & - & + & - \\
\hline Flavonoids & + & + & - & + & - \\
\hline Glycosides & + & + & - & - & - \\
\hline Phenols & - & + & - & - & - \\
\hline Proteins & - & + & - & + & - \\
\hline Saponins & - & - & - & - & - \\
\hline Steroids & + & - & - & + & - \\
\hline
\end{tabular}

The presence of these bioactive compounds in the extract of both the study plant makes them as the potential source for the development of herbal medicine by employing the effective activity of these bioactive compounds. The bioactive compounds are known for a long time for their potential biological activities. They have been exploited for long time for treatment of several diseases. Terminalia catappa is found to provide the shielding effects, against the oxidative stress, due to the anti-oxidant properties of its constituents. This action shows its immune modulatory properties and due to this property it is capable to enhance the function of cells of immune system as well as helps in down regulating the level of TNF- $\alpha$ (Navarro and Mora, 2008). The phenolic compounds present in T. catappa also shows the anti-inflammatory and antiangiogenic properties. Punicalagin, a phenolic compound present in them are found to suppress the TNF- $\alpha$ induced COX-2 (Neyrinck et $a l ., 2013)$ and hence help in reducing the inflammatory responses.
Apart from this T. catappa can also regulate the cholesterol level in blood. It contains flavonoids like quercetin which are hypocholesterolaemic in nature. It regulates the cholesterol level by inhibiting the activity of HMG CoA reductase (Naitik P, 2012). Several studies has been carried out to determine the hyperglycemic activity of T. catappa and it shows that the plant can be employed as an effective natural product for treatment of hyperglycemia as well as is able to reduce the complications of diabetes (Behl and Kotwani, 2017). On the other hand Rumex vesicarius is also a medicinally important plant due to its effective bioactive compounds. The whole plant carries out the medicinal activity and is been widely used for long time in treatment of several diseases especially the digestive tract problems. The ethanolic extract of R. vesicarius is found to show an effective anti-hyperglycemic activity due to its systemic effects on pancreatic mechanism (Reddy et al., 2017). The presence of the phenols and the flavonoids in the extract of $\mathrm{R}$. vesicarius makes it a potential antioxidant agent. The 
intake of these bioactive compounds provides protection against several non-communicable diseases like cancer, cataract and cardiovascular diseases (Imran et al., 2011). The extracts of $\mathrm{R}$. vesicarius are widely employed for the antioxidant and antibacterial assay and the results reveal their potentiality in these two aspects hence the extracts can be used as therapeutic antibacterial agent as well (Laouini and Ouahrani et al., 2017).

\section{CONCLUSION}

The result obtained from the study indicates the solvent dependency of the phytochemical compounds as the kinds of bioactive compounds varied in different solvent for the same extract. The study shows that methanol and ethanol are better solvents for the extraction of the bioactive compound from Terminalia catappa and Rumex vesicarius as maximum numbers of bioactive compounds were present in these extracts for both the sample. The presence of these bioactive compounds in the extract implies the medicinal properties of the extracts. The bioactive compounds impart some unique and effective biological activity to the extract and hence make them potent medicinal agents. The presence of essential bioactive compounds in these extracts makes them the centre of research for their medicinal behaviour.

\section{REFERENCES}

[1] S.M. Ahmed, "Anti-diabetic activity of Terminalia catappa Linn. leaf extracts in alloxan-induced diabetic rats", Iranian J Pharmacol. Ther., Vol. 4, pp. 36-39, 2005.

[2] T. Behl and A. Kotwani, "Proposed mechanisms of Terminalia catappa in hyperglycaemia and associated diabetic complications". Journal of Pharmacy and Pharmacology, Vol. 69, pp. 123-134, 2017.

[3] J.Y. Chung, C. Huang, X. Meng, Z. Dong, and C.S. Yang, "Inhibition of activator protein 1 activity and cell growth by purified green tea and black tea polyphenols in H-ras-transformed cells: structureactivity relationship and mechanisms involved", Cancer Research. Vol. 59, pp. 4610-4617, 1999.
[4] S.A. El-Hawary, N. M. Sokkar, Z.Y. Ali, and M. M. Yehia, "A Profile of Bioactive Compounds of Rumex vesicarius L.", Journal of Food Science, Vol. 76, No. 8, pp. 1195-1202, 2011.

[5] M.C. Gordon, and J.N. David, "Natural product drug discovery in the next millennium", Pharm Biol., Vol. 39, pp. 8-17, 2001.

[6] E.A. Hayouni, M. Abedrabba, M. Bouix, and M. Hamdi, "The effects of solvents and extraction method on the phenolic contents and biological activities in vitri of Tunisian Quercus coccifera $L$. and Juniperus phoenicea L. fruit extracts", Food Chem., Vol. 105, pp. 1126-1134, 2007.

[7] M.M. Imran, M.M. Raja, J. Abdul Basith, and A. Asarudeen, "Determination of total phenol, flavonoid and antioxidant activity of edible mushrooms Pleurotus florida and Pleurotus eous", Int Food Res J, Vol. 18, No. 2, pp. 574-577, 2011.

[8] S.E. Laouini, and M.R Ouahrani., Phytochemical screening, in vitro Antioxidant and Antibacterial activity of Rumex vesicarius L. extract, St. Cerc. St. CICBIA, Vol. 18, No. 4, pp. 367-376, 2017.

[9] H.A.M Mostafa, A.A. EL-Bakry, and Eman, A. Alam, "Evaluation of antibacterial and antioxidant activities of different plant parts of Rumex vesicarius L. (Polygonaceae)" International Journal of Pharmacy and Pharmaceutical Sciences, Vol. 3, No.2, pp. 109-118, 2011.

[10] P. Naitik, "Effect of Terminalia catappa on lipid profile in transplanted fibrosarcoma in rats", Indian J Pharmacol., Vol. 44, pp. 390-392, 2012.

[11] J.F. Navarro-Gonzalez, and C. Mora-Fernandez, "The role of inflammatory cytokines in diabetic nephropathy". J Am Soc Nephrol, Vol. 19, pp. 433-442, 2008.

[12] A.M. Neyrinck, "Polyphenol-rich extract of pomegranate peel alleviates tissue inflammation and hyper cholesterollaemia in high-fat diet-induced obese mice: potential implication of the gut microbiota", Br. J. Nutr., Vol. 109, pp. 802-809, 2013.

[13] P. Prasad and N. Ramakrishnan, "Antioxidant assay of Rumex vesicarius L.", International Journal of Current Research, Vol. 3, No. 11, pp. 074-076, 2012.

[14] N.S Reddy, K. Ramanjaneyulu, V. Sabbani and V. Choday, "In Vitro and in Vivo Antidiabetic Activity of Rumex Vesicarius Leaves Extract in Streptozotocin Induced Diabetic Albino Wister Rats", Journal of Diabetes and Metabolism, Vol. 8, No. 6, pp. 745-749, 2017.

[15] X.H. Tang, L. Gao, Y.M. Fan, L. Z. Xu, X. N. Zhao, and Q. Xu, Mechanism of hepato-protection of Terminalia catappa L. extract on D-galactosamine-induced liver damage. American J. Chin. Med, Vol. 2, pp. 509-519, 2004.

[16] M.J. Yusuf, M.N. Begum, Hoque, and J.U. Chowdhury. Medicinal plants of Bangladesh, BCSIR Chittagong 749, 2009. 